\title{
Effects of Vertical Wind Shear, Radiation, and Ice Clouds on Precipitation Distributions During a Landfall of Severe Tropical Storm, Bilis (2006)
}

\author{
Donghai Wang ${ }^{1,2, *}$, Ping Zhu ${ }^{3}$, Jinfang $\mathrm{Yin}^{1}$, Xiaofan $\mathrm{Li}^{4}$, and Wei-Kuo Tao ${ }^{5}$ \\ ${ }^{I}$ State Key Laboratory of Severe Weather, Chinese Academy of Meteorological Sciences, Beijing, China \\ ${ }^{2}$ Science System and Applications, Inc., Lanham, Maryland, USA \\ ${ }^{3}$ Department of Earth and Environment, Florida International University, Miami, Florida, USA \\ ${ }^{4}$ NOAA/NESDIS/Center for Satellite Applications and Research, Camp Springs, Maryland, USA \\ ${ }^{5}$ NASA/Goddard Space Flight Center, Greenbelt, Maryland, USA
}

Received 24 September 2012, accepted 11 January 2013

\begin{abstract}
Torrential rainfall responses to vertical wind shear, radiation, and ice clouds during the landfall of severe Tropical Storm, Bilis (2006) are investigated via a rainfall partitioning analysis of grid-scale sensitivity experiment data. The rainfall data are partitioned into eight types based on surface rainfall budget. The largest contributions to total rainfall come from local atmospheric moistening, water vapor convergence, and hydrometeor loss/convergence (Type 3;29\%) when the large-scale upward motions occurred only in the upper troposphere on 15 July 2006. When the large-scale upward motion center moved to the mid troposphere on 16 July, Type 3 hydrometeor loss/convergence (26\%) plus local atmospheric drying, water vapor divergence, and hydrometeor loss/convergence (Type 5; 25\%) show equally important contributions to total rainfall.

The exclusion of vertical wind shear primarily reduced Type 5 rainfall because of the weakened hydrometeor loss/ convergence on 16 July. The removal of cloud radiative effects enhances Type 5 rainfall due to increased local atmospheric drying and hydrometeor loss/convergence on 15 July. The elimination of ice clouds generally reduced Type 2 rainfall through the decreases in local atmospheric drying, water vapor convergence, and hydrometeor gain/divergence and Type 3 rainfall over two days.
\end{abstract}

Key words: Vertical wind shear, Radiation, Ice clouds, Rainfall, Severe cloud-resolving model simulation

Citation: Wang, D., P.Zhu, J. Yin, X. Li, and W. K. Tao, 2013: Effects of vertical wind shear, radiation, and ice clouds on precipitation distributions during a landfall of severe tropical storm, Bilis (2006). Terr. Atmos. Ocean. Sci., 24, 383-392, doi: 10.3319/TAO.2013.01.11.02(A)

\section{INTRODUCTION}

The landfall of typhoons over the southeast coast of China over the summer in the Northern Hemisphere produces a major water resource contributor over southern China, but may also cause major floods which lead to tremendous socio-economic losses in southern coast cities. Bilis (2006) was a severe tropical storm that caused 672 fatalities and $\$ 4.4$ billion US dollars in damage to areas of the Philippines, Taiwan, and southeastern China. Wang et al. (2009a, b, 2010a, b , c) conducted a series of two-dimensional (2D) sensitivity cloud-resolving model experiments to study the effects of vertical wind shear, radiation, and ice clouds on convective and stratiform rainfall during the landfall of $\mathrm{Bi}$ -

\footnotetext{
* Corresponding author

E-mail:d.wang@hotmail.com
}

lis. Bilis was surrounded by highs over the northern continent, an eastern subtropics, and southern equatorial areas, which led to its slow movement after its landfall on 15 July 2006. Wang et al. (2009b) found that the exclusion of vertical wind shear decreased convective rainfall on the morning of 16 July 2006 when the imposed large-scale upward motion center moved downward to $6 \mathrm{~km}$. Wang et al. (2010b) showed that the increased model domain mean rainfall resulting from the exclusion of cloud radiative effects is associated with increases in model domain mean net condensation and associated latent heat induced by the enhanced mean radiative cooling on 15 July. The reduction in the mean rain rate resulting from the removal of cloud radiative effects is related to the slowdown in mean net condensation when the enhanced mean radiative cooling fails to increase the mean latent heat release on 16 July. The increased mean rainfall 
on 15 July and decreased mean rainfall on 16 July come mainly from stratiform rainfall regions. Wang et al. (2010b) also revealed that the decreases in the mean rain rate resulting from the elimination of cloud-radiation interaction are associated with the slowdown in the mean hydrometeor loss on 15 July and the suppression in the mean net condensation on 16 July. The decreased mean rainfall is mainly from convective regions on 15 July and stratiform rainfall regions on 16 July. Wang et al. (2010c) found that the decreases in the mean rain rate resulting from the exclusion of ice clouds are associated with decreases in mean net condensation and a change in the mean hydrometeor from a loss to a gain over the two days. The decrease in the mean rain rate is primarily the result of stratiform regions on 15 July and convective regions on 16 July.

Shen et al. (2010) separated 2D grid-scale cloud-resolving model simulation rainfall data during the Tropical Ocean Global Atmosphere Coupled Ocean Atmosphere Response Experiment (TOGA COARE) into eight rainfall types based on different rainfall processes proposed by Gao et al. (2005) and Cui and Li (2006). They showed that the largest rainfall contribution is associated with local atmospheric drying, water vapor divergence, and hydrometeor loss/convergence among the eight rainfall types. They also found that a considerable amount of convective rainfall is associated with regions of water vapor divergence, while a significant amount of stratiform rainfall is associated with regions of water vapor convergence if the scheme developed by Tao et al. (1993) and modified by Sui et al. (1994) is used to separate convective and stratiform rainfall. Convectivestratiform rainfall partitioning schemes have been developed based on the amplitude and spatial variations of radar reflectivity or surface rainfall rate in previous studies (e.g., Churchill and Houze 1984; Caniaux et al. 1994; Steiner et al. 1995). Additional information such as the cloud mixing ratio, vertical motion, and fall speeds of precipitation particles have been also used in separation schemes (e.g., Tao and Simpson 1989; Tao et al. 1993, 2000; Sui et al. 1994; Xu 1995; Lang et al. 2003). Thus, the convective-stratiform rainfall partition may introduce uncertainty. For example, Shen et al. (2012) reveals that about $31 \%$ of convective rainfall is associated with water vapor divergence when they analyzed the same model simulation data in Shen et al. (2010). In contrast, categorization of rainfall into eight types as in Shen et al. (2010) allows a separation of rainfall types based on explicit rainfall processes. Thus, previous convectivestratiform rainfall separation schemes may not show better statistical precipitation characteristics from the analysis of grid-scale data. Unlike previous Bilis studies (Wang et al. 2009a, b, 2010b, c) in which convective-stratiform rainfall partitioning scheme is applied for grid-scale analysis, the rainfall separation scheme based on the surface rainfall scheme proposed by Shen et al. (2010) is applied to the gridscale model simulation data from various sensitivity experi- ments of Bilis. Bilis rainfall is associated with different circulations compared to those during COARE, which rainfall processes play crucial role in production of domain mean rainfall? Since rainfall may be affected by various physical processes and factors, how do vertical wind shear, radiation, and ice clouds affect rainfall processes associated with the development of Bilis?

In this study, effects of vertical wind shear, radiation and ice clouds on torrential rainfall during the landfall of severe tropical storm Bilis (2006) are investigated by analyzing eight rainfall-type data from a series of 2D sensitivity cloud-resolving model simulations. The model and sensitivity experiments are briefly described in the next section. The results are presented in section 3. A summary is given in section 4 .

\section{MODEL AND SENSITIVITY EXPERIMENTS}

The data analyzed in this study are from sensitivity experiments taken from Wang et al. (2009a, b, 2010b,c). These experiments were conducted using the two-dimensional (2D) version of the Goddard cumulus ensemble model (Sui et al. 1994, 1998) modified by Li et al. (1999). The cloudresolving model was originally developed by Soong and Ogura (1980), Soong and Tao (1980), and Tao and Simpson (1993). The model includes prognostic equations for potential temperature, specific humidity, mixing ratios of cloud hydrometeors (cloud water, rain, cloud ice, snow, and graupel). The model has cloud microphysical parameterization schemes (Lin et al. 1983; Rutledge and Hobbs 1983, 1984; Tao et al. 1989; Krueger et al. 1995) and solar and thermal infrared radiation parameterization schemes (Chou et al. 1991, 1998; Chou and Suarez 1994). The model uses cyclic lateral boundary conditions, a horizontal domain of $768 \mathrm{~km}$, a horizontal grid resolution of $1.5 \mathrm{~km}$, and a time step of $12 \mathrm{~s}$. The detailed model descriptions can be found in Gao and Li (2008). The model is integrated from 0800 LST 14 July to 0800 LST 17 July 2006 (a total of 3 days) with the forcing averaged in a rectangular box of $108-116^{\circ} \mathrm{E}, 23-$ $24^{\circ} \mathrm{N}$ (Fig. 1), which is constructed from the reanalysis data from NCEP/GDAS that has a horizontal resolution of $0.5^{\circ} \times$ $0.5^{\circ}$ and a temporal resolution of 4 times per day.

In addition to the control experiment (C) conducted by Wang et al. (2009a), four sensitivity experiments are compared with the control experiment. CNVWS, the experiment that excludes vertical wind shear, is identical to $\mathrm{C}$ except that vertically varying large-scale zonal winds in $\mathrm{C}$ are replaced with mass-weighted mean large-scale zonal winds in CNVWS. CNVWS is compared with $\mathrm{C}$ to examine the effects of vertical wind shear on rainfall. CNCR, the experiment that excludes cloud radiative effects, is identical to $\mathrm{C}$ except that the total hydrometeor mixing ratio (sum of mixing ratios of five cloud species) is set to zero in the calculations of optical thickness and radiation. CNCRI, the experi- 
ment that excludes cloud-radiation interaction, is identical to $\mathrm{C}$ except that in CNCRI the cloud-radiation interaction is not allowed and vertical radiation profiles at each grid is imposed with same vertical radiation profiles averaged over model domain mean from C. CNCR and CNCRI are respectively compared with $\mathrm{C}$ to study the effects of cloud radiative processes and cloud-radiation interaction on rainfall. CNIM, the experiment that excludes ice clouds, is identical to $\mathrm{C}$ except that the ice hydrometeor mixing ratio is set to zero in CNIM. The comparison between CNIM and C shows the effects of ice clouds on rainfall. Five experiments are summarized in Table 1.

Based on surface rainfall budget proposed by Gao et al. (2005) and Cui and $\mathrm{Li}(2006)$, the surface rain rate $\left(P_{S}\right)$ is determined by local vapor change $\left(Q_{W V T}\right)$, water vapor convergence $\left(Q_{W V F}\right)$, surface evaporation $\left(Q_{W V E}\right)$, and hydrometeor change/convergence $\left(Q_{C M}\right)$, i.e.,

$P_{s}=Q_{W V T}+Q_{W V F}+Q_{W V E}+Q_{C M}$

where

(a)

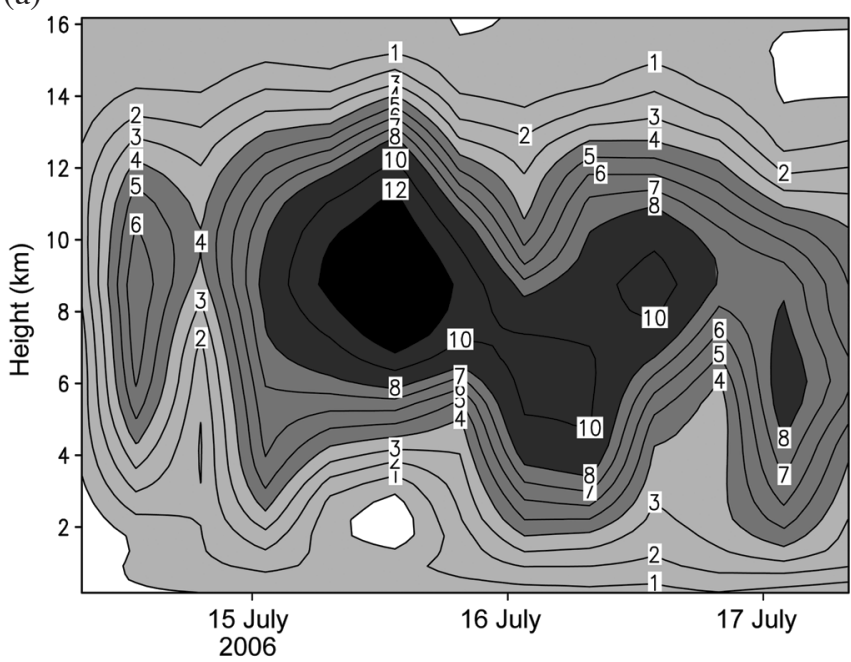

$Q_{W V T}=-\frac{\partial\left[q_{v}\right]}{\partial t}$

$Q_{W V F}=-\left[\bar{u}^{o} \frac{\partial{\overline{q_{v}}}^{o}}{\partial x}\right]-\left[\bar{w}^{o} \frac{\partial \overline{q_{v}}}{\partial z}\right]-\left[\frac{\partial\left(u^{\prime} q_{v}^{\prime}\right)}{\partial x}\right]-\left[\bar{u}^{o} \frac{\partial q_{v}^{\prime}}{\partial x}\right]$

$-\left[\bar{w}^{o} \frac{\partial q_{v}^{\prime}}{\partial z}\right]-\left[w^{\prime} \frac{\partial \overline{q_{v}}}{\partial z}\right]$

$Q_{W V E}=E$

$Q_{C M}=-\frac{\partial\left[q_{5}\right]}{\partial t}-\left[\frac{\partial\left(u q_{5}\right)}{\partial x}\right]$

Here, $q_{v}$ is specific humidity; $u$ and $w$ are zonal and vertical wind components, respectively; $E_{s}$ is surface evaporation rate; $q_{5}=q_{c}+q_{r}+q_{i}+q_{s}+q_{g}, q_{c}, q_{r}, q_{i}, q_{s}, q_{g}$ are the mixing ratios of cloud water, raindrops, cloud ice, snow, and graupel, respectively; the overbar denotes model domain mean; prime is a perturbation from the domain mean; [ ] is (b)

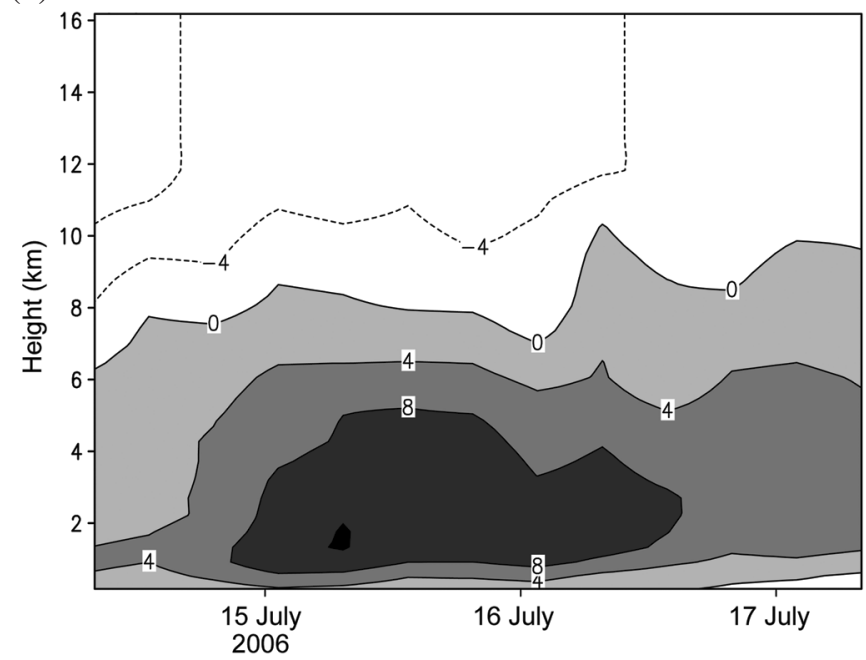

Fig. 1. Time-height distributions of (a) vertical velocity $\left(\mathrm{cm} \mathrm{s}^{-1}\right)$ and (b) zonal wind ( $\left.\mathrm{m} \mathrm{s}^{-1}\right)$ from 0800 LST 14 July - 0800 LST 17 July 2006.

Table 1. Summary of experiments.

\begin{tabular}{c|l}
\hline \multicolumn{1}{c|}{ C } & \multicolumn{1}{c}{ Control experiment } \\
\hline CNVWS & $\begin{array}{l}\text { Vertically varying large-scale zonal winds in C are replaced with mass-weighted mean large-scale } \\
\text { zonal winds in CNVWS }\end{array}$ \\
CNCR & $\begin{array}{l}\text { Total hydrometeor mixing ratio (sum of mixing ratios of five cloud species) is set to zero in the calcula- } \\
\text { tions of optical thickness and radiation } \\
\text { CNCRI }\end{array}$ \\
$\begin{array}{l}\text { Cloud-radiation interaction is not allowed in CNCRI and vertical radiation profiles at each grid in CN- } \\
\text { CRI is imposed with same vertical radiation profiles averaged over model domain mean from C } \\
\text { CNIM }\end{array}$ & The ice hydrometeor mixing ratio is set to zero \\
\hline
\end{tabular}


a mass integration; and superscript ${ }^{\circ}$ is an imposed NCEP/ GDAS value. In Eq. (1), $Q_{W V T}, Q_{W V F}$ and $Q_{C M}$ can be positive or negative, whereas surface evaporation $\left(Q_{W V E}\right)$ is positive. Following Shen et al. (2010), grid-scale rainfall simulation data are categorized into the eight rainfall types based on different rainfall processes (Table 2). The analysis of rainfall Type 8 associated with water vapor divergence, local atmospheric moistening, and hydrometeor gain/divergence is not shown in this study because its rain rate is zero.

\section{RESULTS}

\subsection{C: The Control Experiment}

The calculation of daily mean surface rain rate for each rainfall type in the control experiment (C) shows that the highest rain rate comes from the Type 3 rainfall associated with local atmospheric moistening, water vapor convergence and hydrometeor loss/convergence $\left(0.78 \mathrm{~mm} \mathrm{~h}^{-1}\right)$ on 15 July and from Type $3\left(0.79 \mathrm{~mm} \mathrm{~h}^{-1}\right)$ and the rainfall Type 5 associated with local atmospheric drying, water vapor divergence and hydrometeor loss/convergence $\left(0.76 \mathrm{~mm} \mathrm{~h}^{-1}\right)$ on 16 July (Fig. 2) because these rainfalls cover the largest areas (Fig. 3). The calculations in percentage of rain amount over the total rainfall amount (PRA) reveal that Type 3 has rainfall contributions of 29.07 and $25.51 \%$, respectively, on 15 and 16 July (Fig. 4). Type 5 contributes $24.71 \%$ to the total rainfall on 16 July. This is different from the result found by Shen et al. (2010) in which the largest rainfall contribution comes from Type 5 (30.8\%) during TOGA COARE. The difference in the largest rainfall contribution may result from the difference in the vertical structures of imposed large-scale vertical velocity. The upward motions during COARE usually occur throughout the troposphere and their centers appear around $8-10 \mathrm{~km}$. In contrast, Bilis has strong upward motions in the upper troposphere and weak downward motions in the lower troposphere on 15 July and the maximum upward motions extend to $6 \mathrm{~km}$ and downward motions vanish in the morning of 16 July.

Due to the small fractional rainfall coverage, the Type 6 rainfall associated with local atmospheric drying, water vapor divergence and hydrometeor gain/divergence and Type 7 rainfall associated with local atmospheric moistening, water vapor divergence and hydrometeor loss/convergence have the lowest rain rates over the two days which have the smallest PRA of about $2 \%$ among the seven types. Although the fractional coverage is small, the Type 1 rainfall associated with local atmospheric drying, water vapor convergence and hydrometeor loss/convergence contribute more than $10 \%$ to total rainfall. The Type 2 rainfall associated with local atmospheric drying, water vapor convergence and hydrometeor gain/divergence and Type 4 associated with local atmospheric moistening, water vapor convergence and hydrometeor gain/divergence have mean rain rates of about $0.5 \mathrm{~mm} \mathrm{~h}^{-1}$ over both days, although Type 2 covers the smaller area than Type 4 does. The two types have PRA of about $17-19 \%$. Since Type 1 covers the smaller area on 15 July (15.36\%) than on 16 July (30.22\%), the mean rain rate of Type 1 is lower on 15 July $\left(0.40 \mathrm{~mm} \mathrm{~h}^{-1}\right)$ than on 16 July $\left(0.76 \mathrm{~mm} \mathrm{~h}^{-1}\right)$. As a result, its PRA is much smaller on 15 July (14.96\%) than that on 16 July (24.71\%).

Local atmospheric drying, water vapor convergence and hydrometeor loss/convergence are equally important in production of Type 1 rainfall (Figs. 5 - 7). Note that surface evaporation is not shown in these figures because it is negligibly small in the surface rainfall budget. Although water vapor convergence is much larger in Type 4 than in Type 2 , it is offset by local atmospheric moistening and hydrometeor gain/convergence in Type 4 and water vapor convergence and local atmospheric drying are balanced by hydrometeor gain/convergence in Type 2. Thus, their mean rain rates are similar. Type- 3 rainfall corresponds to hydrometeor loss/ convergence while water vapor convergence moistens local

Table 2. Summary of eight rainfall types.

\begin{tabular}{cc}
\hline Type & Description \\
\hline 1 & Water vapor convergence $\left(Q_{W V F}>0\right)$, local atmospheric drying $\left(Q_{W V T}>0\right)$, and hydrometeor loss/convergence $\left(Q_{C M}>0\right)$ \\
2 & Water vapor convergence $\left(Q_{W V F}>0\right)$, local atmospheric drying $\left(Q_{W V T}>0\right)$, and hydrometeor gain/divergence $\left(Q_{C M}<0\right)$ \\
3 & Water vapor convergence $\left(Q_{W V F}>0\right)$, local atmospheric moistening $\left(Q_{W V T}<0\right)$, and hydrometeor loss/convergence $\left(Q_{C M}>0\right)$ \\
4 & Water vapor convergence $\left(Q_{W V F}>0\right)$, local atmospheric moistening $\left(Q_{W V T}<0\right)$, and hydrometeor gain/divergence $\left(Q_{C M}<0\right)$ \\
5 & Water vapor divergence $\left(Q_{W V F}<0\right)$, local atmospheric drying $\left(Q_{W V T}>0\right)$, and hydrometeor loss/convergence $\left(Q_{C M}>0\right)$ \\
6 & Water vapor divergence $\left(Q_{W V F}<0\right)$, local atmospheric drying $\left(Q_{W V T}>0\right)$, and hydrometeor gain/divergence $\left(Q_{C M}<0\right)$ \\
7 & Water vapor divergence $\left(Q_{W V F}<0\right)$, local atmospheric moistening $\left(Q_{W V T}<0\right)$, and hydrometeor loss/convergence $\left(Q_{C M}>0\right)$ \\
8 & Water vapor divergence $\left(Q_{W V F}<0\right)$, local atmospheric moistening $\left(Q_{W V T}<0\right)$, and hydrometeor gain/divergence $\left(Q_{C M}<0\right)$ \\
\hline
\end{tabular}



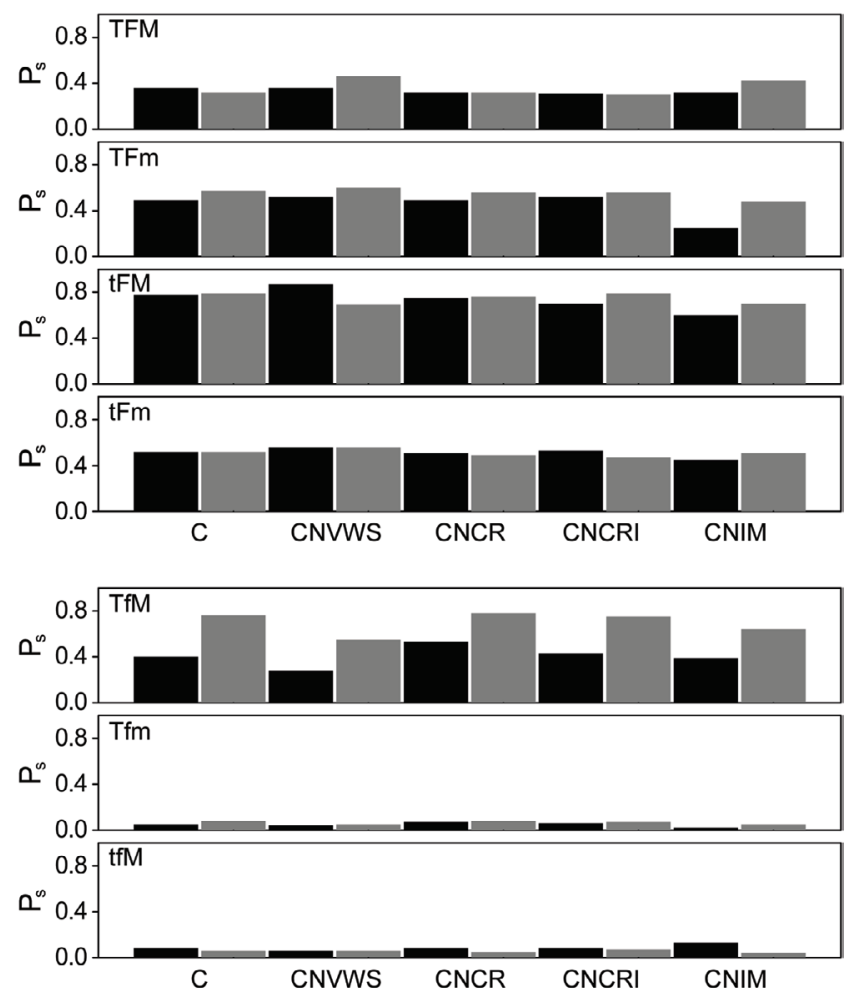

Fig. 2. Daily means of rain rate $\left(P_{S}\right)$ for TFM, TFm, tFM, tFm, TfM, Tfm, tfM, tfm in C, CNVWS, CNCR, CNCRI, and CNIM on 15 (black bar) and 16 (grey bar) July 2006 [Unit: $\mathrm{mm} \mathrm{h}^{-1}$ ]
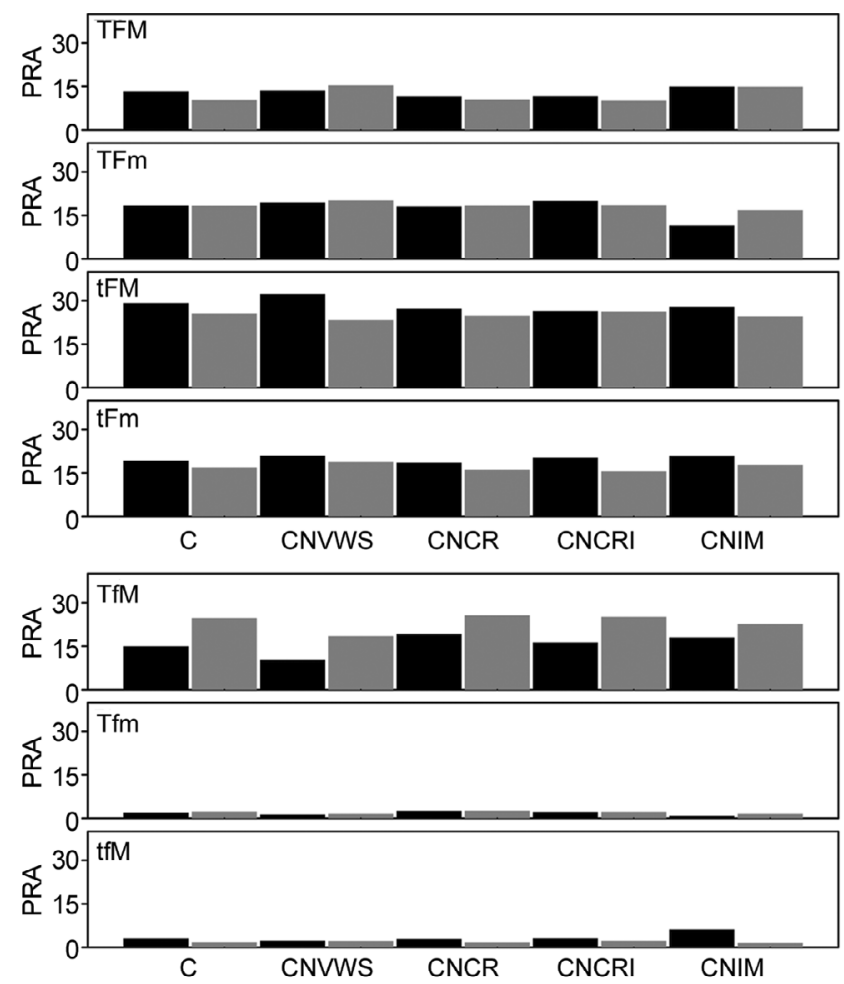

Fig. 4. Percentage of rain amount over total rainfall amount (PRA) in TFM, TFm, tFM, tFm, TfM, Tfm, tfM, tfm in C, CNVWS, CNCR, CNCRI, and CNIM on 15 (black bar) July and 16 (grey bar) July 2006 [Unit: \%].
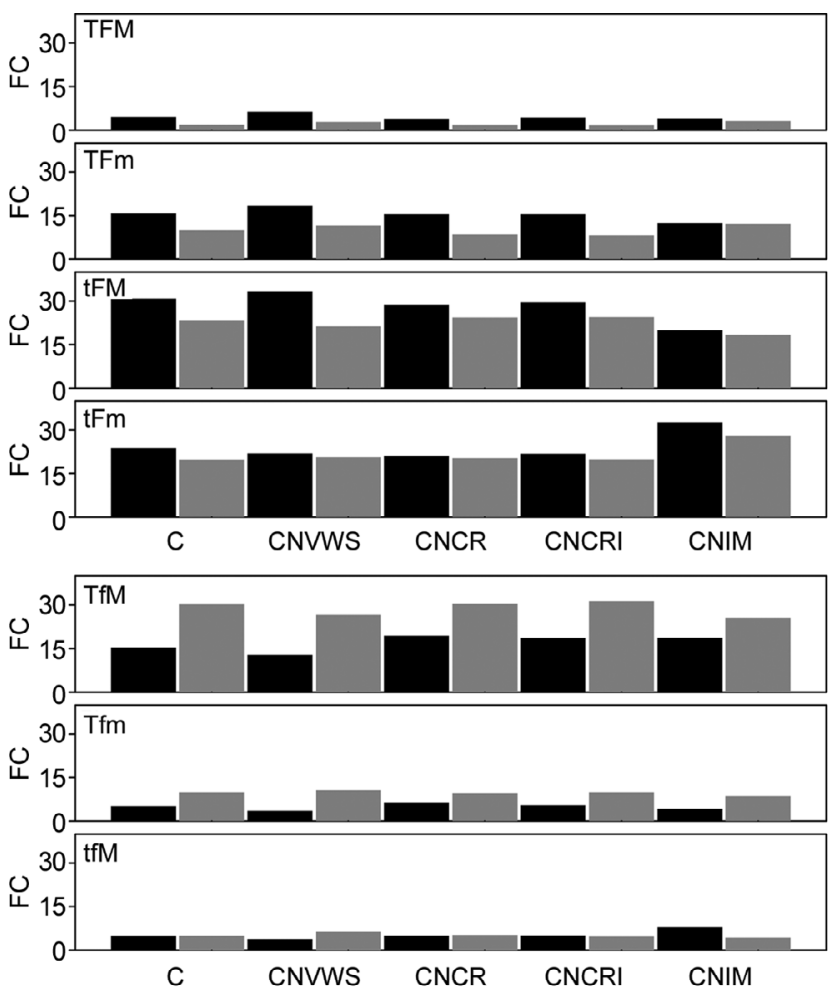

Fig 3. Daily means of fractional coverage (FC) for TFM, TFm, tFM, tFm, TfM, Tfm, tfM, tfm in C, CNVWS, CNCR, CNCRI, and CNIM on 15 (black bar) July and 16 (grey bar) July 2006 [Unit: \%].
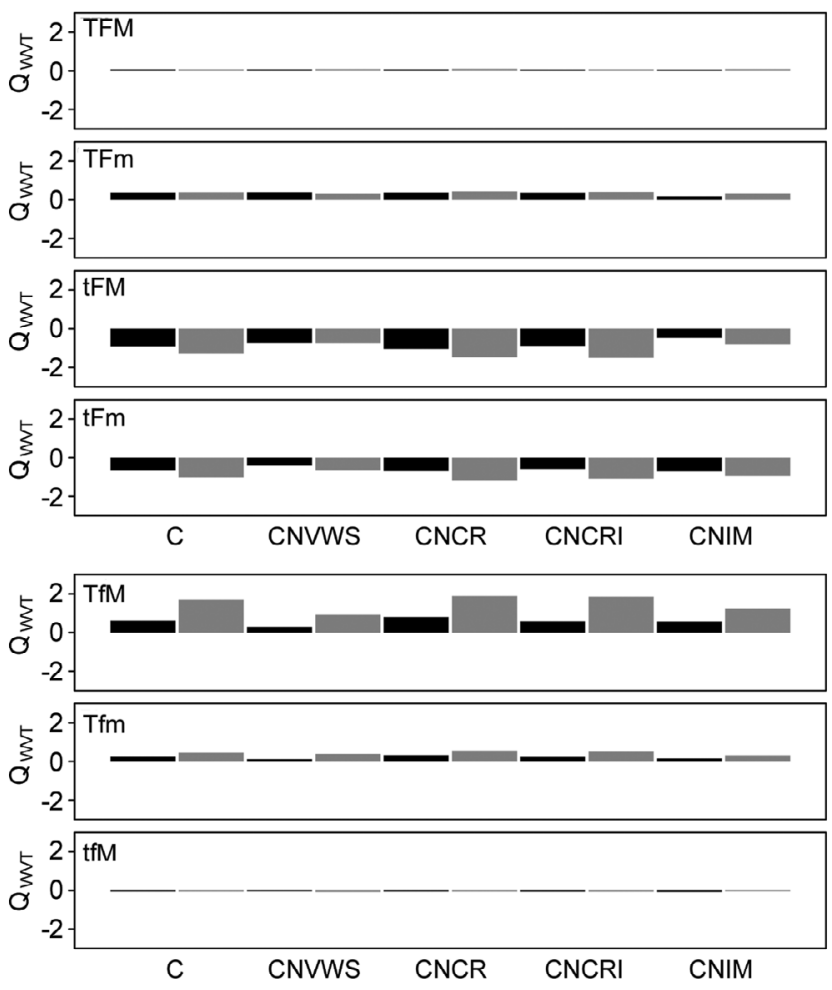

Fig. 5. As in Fig. 2 except for local change of water vapor $\left(Q_{W V T}\right)$. 

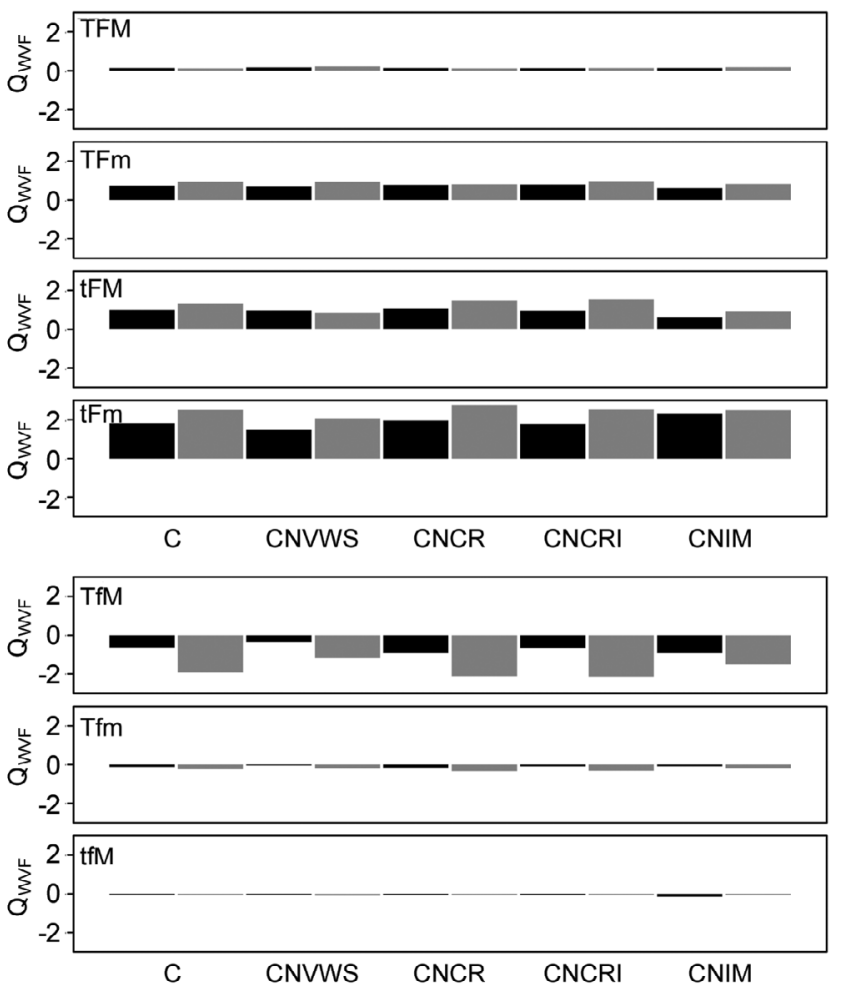

Fig. 6. As in Fig. 2 except for water vapor convergence $\left(Q_{W V F}\right)$.

atmosphere. Type-5 rain is associated with hydrometeor loss/convergence while the water vapor divergence dries local atmosphere. The hydrometeor loss/convergence rate on 16 July is more than twice larger than that on 15 July, which leads to a much higher mean rain rate on 16 July than on 15 July. Types 6 and 7 retain the lowest rain rates and have the smallest rainfall contributions regardless of vertical wind shear, radiation and ice clouds. Thus, effects of vertical wind shear, radiation, and ice clouds on these surface rainfall budgets are not explored in the following discussion.

\subsection{CNVWS Versus C: Effects of Vertical Wind Shear}

The exclusion of vertical wind shear increases the rain rate associated with local atmospheric drying, water vapor convergence and hydrometeor loss/convergence (Type 1) by $43.8 \%$ (Fig. 2) and the PRA by $49.0 \%$ (Fig. 4 ) on 16 July. In contrast, its rain rate and PRA are not sensitive to the vertical wind shear on 15 July. The increase in the rain rate on 16 July is associated with the increases in fractional coverage (49.2\%) (Fig. 3) and water vapor convergence (90.9\%) (Fig. 6). The removal of vertical wind shear decreases the rain rate and PRA of Type 5 by about $30 \%$ over the two-day period (Fig. 2) due to the shrink of rainfall area (Fig. 3) and the decrease in hydrometeor loss/convergence as a result of cancelation between the decreases in local atmospheric drying and water vapor divergence (Fig. 7). The elimination of
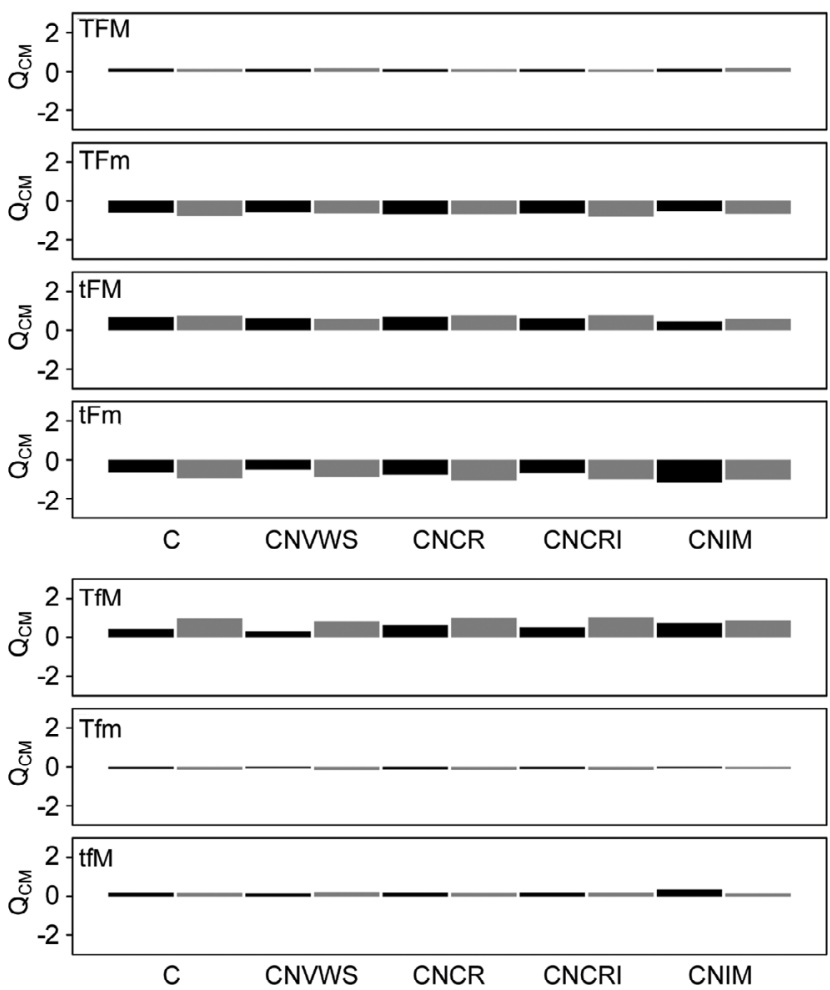

Fig. 7. As in Fig. 2 except for hydrometeor change/convergence $\left(Q_{C M}\right)$.

vertical wind shear increases the Type- 3 rain rate by $11.5 \%$ through the increased fractional coverage and weakened local atmospheric moistening on 15 July whereas it decreases the rain rate by $12.7 \%$ (Fig. 2) through the shrink of fractional coverage (Fig. 3) and the weakened hydrometeor loss/ convergence on 16 July (Fig. 7). The exclusion of vertical wind shear increases the rain rates of Types 2 and 4 by 5 $7 \%$ over the two days (Fig. 2) because of the expansion of rainfall area (Fig. 3), the weakened hydrometeor gain/divergence (Fig. 7) and, the decreased local atmospheric moistening (Fig. 5).

\subsection{CNCR Versus C: Cloud Radiative Effects}

The largest change in the rain rate resulting from the exclusion of cloud radiative effects occurred with Type 5 on 15 July when the rain rate increased from $0.40 \mathrm{~mm} \mathrm{~h}^{-1}$ in $\mathrm{C}$ to $0.53 \mathrm{~mm} \mathrm{~h}^{-1}$ in CNCR (Fig. 2). Its PRA on that day increased from $14.96 \%$ in $\mathrm{C}$ to $19.23 \%$ in CNCR (Fig. 4). The increase in rain rate was associated with the expansion of rainfall area from $15.36 \%$ in C to $19.43 \%$ in CNCR (Fig. 3) and increased in hydrometeor loss/convergence from $0.44 \mathrm{~mm} \mathrm{~h}^{-1}$ in $\mathrm{C}$ to $0.64 \mathrm{~mm} \mathrm{~h}^{-1}$ in CNCR and local atmospheric drying from $0.61 \mathrm{~mm} \mathrm{~h}^{-1}$ in $\mathrm{C}$ to $0.80 \mathrm{~mm} \mathrm{~h}^{-1}$ in CNCR (Fig. 5). The removal of cloud radiative effects only caused slight increases in the rain rate and PRA of Type 5 on 16 July because of the small expansion of rainfall area 
and offset between the increased in local atmospheric drying and water vapor divergence. The elimination of cloud radiative effects generally decreases the rain rate associated with water vapor convergence (Types $1-4$ ) by about $2-11 \%$ through the shrink of rainfall area (Fig. 3) and the increases in local atmospheric moistening and hydrometeor gain/divergence (Figs. 5 - 7) and generally shrinks the associated PRA (Fig. 4).

\subsection{CNCRI Versus C: Effects of Cloud-Radiation Inter- action}

The exclusion of cloud-radiation interaction decreases the rain rates and PRA of Types 1 and 3 whereas it increases the rain rates and PRA of Types 2, 4, and 5 on 15 July (Figs. 2 and 4). The rainfall decrease is associated with the shrink of rainfall area (Fig. 3) and the reductions in local atmospheric drying, water vapor convergence and hydrometeor loss/convergence in Type 1 (Figs. 5 - 7) and the decreases in hydrometeor loss/convergence and water vapor convergence in Type 3 . The increases in rain rate correspond to the enhanced water vapor convergence in Type 2 and the expansion of rainfall area and the enhanced hydrometeor loss/convergence in Type 5 . The removal of cloud-radiation interaction decreases the rain rates and PRA of Types 1 and 3 on 16 July. The decreases in rain rate are related to the reduction in hydrometeor loss/convergence while the increase in water vapor convergence enhances local atmospheric moistening in Type 4 and the shrink of rainfall area and the weakened hydrometeor loss/convergence. The elimination of cloud-radiation interaction slightly decreases the rain rates of Types 2 and 5 but it slightly increases the PRA because of the decrease in domain mean rain rate from $\mathrm{C}$ to CNCRI on 16 July (Table 3 ).

\subsection{CNIM Versus C: Effects of Ice Clouds}

The exclusion of ice clouds generally decreases the rain rates. The decrease in domain mean rain rate results from the decreases in rain rates of Types 2 and 3 in the two days (Table 3 and Fig. 2). The decrease in Type-2 rainfall is related to the decreases in local atmospheric drying and water vapor convergence (Figs. 5 - 7), whereas the decrease in Type-3 rainfall is associated with the shrink of rainfall area (Fig. 3) and the decreases in water vapor convergence and hydrometeor loss/convergence. The rainfall reductions are larger on 15 July than on 16 July because the decrease in local atmospheric drying in Type 2 is much larger on 15 July than 16 July and the decrease in local atmospheric moistening is smaller and the decrease in hydrometeor loss/ convergence in Type 3 is larger on 15 July than on 16 July. Since the rain rate of Type 2 is smaller than that of Type 3 on 15 July, the decrease in PRA of Type 2 is much larger than that of Type 3 (Fig. 4).
Table 3. Daily and model domain means of rain rate $\left(P_{S}\right)$ in $\mathrm{C}, \mathrm{CN}$ VWS, CNCR, CNCRI, and CNIM on 15 and 16 July 2006 [Unit: $\left.\mathrm{mm} \mathrm{h}^{-1}\right]$.

\begin{tabular}{cccccc}
\hline & C & CNVWS & CNCR & CNCRI & CNIM \\
\hline 15 July & 2.68 & 2.69 & 2.75 & 2.63 & 2.15 \\
16 July & 3.10 & 2.97 & 3.04 & 3.01 & 2.84 \\
\hline
\end{tabular}

In Type 1, the exclusion of ice clouds decreases the rain rate and PRA on 15 July whereas it increases the rain rate and PRA on 16 July. The rainfall decrease on 15 July is associated with the shrink of rainfall area and the weakened local atmospheric drying and the weakened hydrometeor loss/convergence. The rainfall increase on 16 July is related to the expansion of rainfall area and the enhanced water vapor convergence and enhanced hydrometeor loss/ convergence.

The removal of ice clouds decreases the Type-5 rainfall on 16 July, but it barely changes the rain rate on 15 July. The rainfall decrease on 16 July corresponds to the shrink of rainfall area and the suppressed hydrometeor loss/ convergence due to the offset between the decreases in local atmospheric drying and water vapor divergence. The rainfall similarity in C and CNIM on 15 July results from the balance between the increases in water vapor divergence and hydrometeor loss/convergence. The decrease in Type-5 rainfall on 16 July leads to the decrease in PRA. Although the rain rates of Type 5 are similar in C and CNIM on 15 July, the domain mean rain rate in CNIM is lower than in $\mathrm{C}$ (Table 3). The PRA of Type 5 on 15 July is smaller in CNIM than in $\mathrm{C}$.

\section{SUMMARY}

Effects of vertical wind shear, radiation and ice clouds on rainfall during a landfall of severe tropical storm Bilis (2006) was investigated through the rainfall partitioning analysis with a series of grid-scale sensitivity experiment data from Wang et al. (2009a, b, 2010b, c). The experiments were conducted with a two-dimensional cloud-resolving model. The model was integrated for 3 days with imposed zonally-uniform vertical velocity, zonal wind, horizontal temperature and vapor advection from NCEP/GDAS data. The analysis was conducted on 15 and 16 July during the torrential rainfall event because vertical profiles of imposed large-scale vertical velocity are strong upward motions in the upper troposphere and weak downward motions in the lower troposphere on 15 July and downward movement of upward motion center to the mid troposphere in the morning of 16 July. The scheme partitioned grid-scale rainfall simulation data into eight rainfall types. The major results include: 
(1) The exclusion of vertical wind shear increases the rainfall associated with local atmospheric drying, water vapor convergence and hydrometeor loss/convergence by more than $40 \%$ on 16 July whereas it decreases the rainfall associated with local atmospheric drying, water vapor divergence and hydrometeor loss/convergence by about $30 \%$ over the two days. The rainfall increase is associated with the expansion of rainfall area and the increases in water vapor convergence and hydrometeor loss/convergence. The rainfall reductions are related to the decreases in rainfall area and hydrometeor loss/convergence as the weakened water vapor divergence suppressed local atmospheric drying.

(2) The removal of cloud radiative effects increases the rainfall associated with local atmospheric drying, water vapor divergence and hydrometeor loss/convergence by more than $30 \%$ on 15 July. The rainfall increase corresponds to the increases in rainfall area and local atmospheric drying and hydrometeor loss/convergence. The elimination of cloud-radiation interaction reduces the rainfall associated local atmospheric drying, water vapor convergence and hydrometeor loss/convergence by about $14 \%$ and the rainfall associated with local atmospheric moistening, water vapor convergence and hydrometeor loss/convergence by about $10 \%$ through the weakened hydrometeor loss/convergence on 15 July. The exclusion of cloud-radiation interaction reduces the rainfall with local atmospheric moistening, water vapor convergence and hydrometeor gain/divergence by about $10 \%$ through the enhanced local atmospheric moistening and hydrometeor gain/divergence on 16 July.

(3) The exclusion of ice clouds decreases the rainfall with local atmospheric drying, water vapor convergence and hydrometeor gain/divergence by about $50 \%$ through the decreases in rainfall area and local atmospheric drying and water vapor convergence and the rainfall associated with local atmospheric moistening, water vapor convergence, and hydrometeor loss/convergence rate by about $23 \%$ through the decreases in rainfall area and water vapor convergence and hydrometeor loss/convergence on 15 July. These two types are also major contributors for the reduction in domain mean rainfall on 16 July, but the largest contributor is the rainfall associated with local atmospheric drying, water vapor convergence, and hydrometeor loss/convergence.

(4) The largest contribution to total rainfall is from tFM (29\%) on 15 July and is from tFM (26\%) and TfM (25\%) on 16 July, which is different from the result found in Shen et al. (2010) during TOGA COARE in which the largest rainfall contribution is from TfM $(31 \%)$ and $\mathrm{tFM}$ only contributes about $19 \%$ to total rainfall. The largest decrease in rainfall contribution comes from TfM in the two days when vertical wind shear is excluded and from tFM on 15 July when cloud-radiation interaction is excluded and from TFm on 15 July when ice clouds are removed from the model. The largest increase in rainfall contribution is from TfM on 15 July when cloud radiative effects are cut off.

Acknowledgements The authors thank Prof. B. Jou at the National Taiwan University and an anonymous reviewer for their constructive comments. This research is jointly supported by the State Key Basic Research Development Program (2012CB417204, 2009CB421504), the R\&D Special Fund for Public Welfare Industry (meteorology) by the Ministry of Finance and the Ministry of Science and Technology (GYHY200806007, GYHY201006014 and GYHY201206039), the National Natural Science Foundation (40875022, 40633016, and 41175064), and the Basic Research Project of the State Key Laboratory of Severe Weather, Chinese Academy of Meteorological Sciences.

\section{REFERENCES}

Caniaux, G., J.-L. Redelsperger, and J.-P. Lafore, 1994: A numerical study of the stratiform region of a fast-moving squall line. Part I: General description and water and heat budgets. J. Atmos. Sci., 51, 2046-2074, doi: 10.1175/1520-0469(1994)051<2046:ANSOTS>2.0. $\mathrm{CO} ; 2$. [Link]

Chou, M.-D. and M. J. Suarez, 1994: An efficient thermal infrared radiation parameterization for use in general circulation model. NASA Tech. Memo. 104606, vol. 3, 85 pp, available from NASA/Goddard Space Flight Center, Code 913, Greenbelt, MD 20771.

Chou, M. D., D. P. Kratz, and W. Ridgway, 1991: Infrared radiation parameterizations in numerical climate models. J. Climate, 4, 424-437, doi: 10.1175/1520-0442 (1991)004<0424:IRPINC>2.0.CO;2. [Link]

Chou, M. D., M. J. Suarez, C. H. Ho, M. M.-H. Yan, and K. T. Lee, 1998: Parameterizations for cloud overlapping and shortwave single-scattering properties for use in general circulation and cloud ensemble models. $J$. Climate, 11, 202-214, doi: 10.1175/1520-0442(1998) $011<0202:$ PFCOAS>2.0.CO;2. [Link $]$

Churchill, D. D. and R. A. Houze Jr., 1984: Development and structure of winter monsoon cloud clusters on $10 \mathrm{De}$ cember 1978. J.Atmos. Sci., 41, 933-960, doi: 10.175/15 20-0469(1984)041<0933:DASOWM>2.0.CO;2. [Link]

Cui, X. and X. Li, 2006: Role of surface evaporation in surface rainfall processes. J. Geophys. Res., 111, D17112, doi: 10.1029/2005JD006876. [Link]

Gao, S. and X. Li, 2008: Cloud-resolving Modeling of Convective Processes, Springer, Dordrecht, 206 pp.

Gao, S., X. Cui, Y. Zhu, and X. Li, 2005: Surface rainfall processes as simulated in a cloud-resolving model. $J$. Geophys.Res., 110,D10202, doi: 10.1029/2004JD0054 67. [Link] 
Krueger, S. K., Q. Fu, K. N. Liou, and H.-N. S. Chin, 1995: Improvements of an ice-phase microphysics parameterization for use in numerical simulations of tropical convection. J. Appl. Meteorol., 34, 281-287, doi: 10. 1175/1520-0450-34.1.281. [Link]

Lang, S., W. K. Tao, J. Simpson, and B. Ferrier, 2003: Modeling of convective-stratiform precipitation processes: Sensitivity to partitioning methods. J. Appl. Meteorol., 42, 505-527, doi: 10.1175/1520-0450(2003)042<0505: MOCSPP $>2.0 . C O ; 2$. [Link]

Li, X., C. H. Sui, K. M. Lau, and M. D. Chou, 1999: Largescale forcing and cloud-radiation interaction in the tropical deep convective regime. J. Atmos. Sci., 56, 3028-3042, doi: 10.1175/1520-0469(1999)056<3028: LSFACR $>2.0 . C O ; 2$. [Link]

Lin, Y. L., R. D. Farley, and H. D. Orville, 1983: Bulk parameterization of the snow field in a cloud model. $J$. Climate Appl.Meteorol., 22, 1065-1092, doi: 10.1175/ 1520-0450(1983)022<1065:BPOTSF>2.0.CO;2. [Link]

Rutledge, S. A. and P. V. Hobbs, 1983: The mesoscale and microscale structure and organization of clouds and precipitation in midlatitude cyclones. VIII: A model for the "seeder-feeder" process in warm-frontal rainbands. J. Atmos. Sci., 40, 1185-1206, doi: 10.1175/1520-04 69(1983)040<1185:TMAMSA > 2.0.CO;2. [Link]

Rutledge, S. A. and P. V. Hobbs, 1984: The mesoscale and microscale structure and organization of clouds and precipitation in midlatitude cyclones. XII: A diagnostic modeling study of precipitation development in narrow cold-frontal rainbands. J. Atmos. Sci., 41, 2949-2972, doi: 10.1175/1520-0469(1984)041<2949:TMAMSA> 2.0.CO;2. [Link]

Shen, X., Y. Wang, N. Zhang, and X. Li, 2010: Precipitation and cloud statistics in the deep tropical convective regime. J. Geophys. Res., 115, D24205, doi: 10.10 29/2010JD014481. [Link]

Shen, X., J. Liu, and X. Li, 2012: Evaluation of convectivestratiform rainfall separation schemes by precipitation and cloud statistics. J. Trop. Meteorol., 18, 98-107.

Soong, S. T. and W. K. Tao, 1980: Response of deep tropical cumulus clouds to Mesoscale processes. J. Atmos. Sci., 37, 2016-2034, doi: 10.1175/1520-0469(1980)03 7<2016:RODTCC >2.0.CO;2. [Link]

Soong, S. T. and Y. Ogura, 1980: Response of tradewind cumuli to large-scale processes. J. Atmos. Sci., 37, 2035-2050, doi: 10.1175/1520-0469(1980)037<2035: ROTCTL $>2.0 . C O ; 2$. [Link]

Steiner, M., R. A. Houze Jr., and S. E. Yuter, 1995: Climatological characterization of three-dimensional storm structure from operational radar and rain gauge data. $J$. Appl. Meteorol., 34, 1978-2007, doi: 10.1175/1520-04 50(1995)034<1978:CCOTDS>2.0.CO;2. [Link]

Sui, C. H., K. M. Lau, W. K. Tao, and J. Simpson, 1994:
The tropical water and energy cycles in a cumulus ensemble model. Part I: Equilibrium climate. J. Atmos. Sci., 51, 711-728, doi: 10.1175/1520-0469(1994)051 $<0711$ :TTWAEC $>2.0 . \mathrm{CO} ; 2$. [Link]

Sui, C. H., X. Li, and K. M. Lau, 1998: Radiative-convective processes in simulated diurnal variations of tropical oceanic convection. J. Atmos. Sci., 55, 2345-2357, doi: 10.1175/1520-0469(1998)055<2345:RCPISD >2.0. CO;2. [Link]

Tao, W. K. and J. Simpson, 1989: Modeling study of a tropical squall-type convective line. J. Atmos. Sci., 46, 177202, doi: 10.1175/1520-0469(1989)046<0177:MSOA TS $>2.0 . C O ; 2$. [Link]

Tao, W. K. and J. Simpson, 1993: The Goddard Cumulus Ensemble model. Part I: Model description. Terr. Atmos. Ocean. Sci., 4, 35-72.

Tao, W. K, J. Simpson, and M. McCumber, 1989: An icewater saturation adjustment. Mon. Weather Rev., 117, 231-235, doi: 10.1175/1520-0493(1989)117<0231:AI WSA $>2.0 . C O ; 2$. [Link]

Tao, W. K., J. Simpson, C. H. Sui, B. Ferrier, S. Lang, J. Scala, M. D. Chou, and K. Pickering, 1993: Heating, moisture, and water budgets of tropical and midlatitude squall lines: Comparisons and sensitivity to longwave radiation. J.Atmos. Sci., 50, 673-690, doi: 10.1175/152 0-0469(1993)050<0673:HMAWBO>2.0.CO;2. [Link]

Tao, W. K., S. Lang, J. Simpson, W. S. Olson, D. Johnson, B. Ferrier, C. Kummerow, and R. Adler, 2000: Vertical profiles of latent heat release and their retrieval for TOGA COARE convective systems using a cloud resolving model, SSM/I, and ship-borne radar data. $J$. Meteorol. Soc. Jpn., 78, 333-355.

Wang, D., X. Li, W. K. Tao, Y. Liu, and H. Zhou, 2009a: Torrential rainfall processes associated with a landfall of severe tropical storm Bilis (2006): A two-dimensional cloud-resolving modeling study. Atmos. Res., 91, 94-104, doi: 10.1016/j.atmosres.2008.07.005. [Link]

Wang, D., X. Li, W. K. Tao, and Y. Wang, 2009b: Effects of vertical wind shear on convective development during a landfall of severe tropical storm Bilis (2006). Atmos. Res., 94, 270-275, doi: 10.1016/j.atmosres.2009. 06.004. [Link]

Wang, D., X. Li, and W. K. Tao, 2010a: Responses of vertical structures in convective and stratiform regions to large-scale forcing during the landfall of severe tropical storm Bilis (2006). Adv. Atmos. Sci., 27, 33-46, doi: 10.1007/s00376-009-8139-y. [Link]

Wang, D., X. Li, and W. K. Tao, 2010b: Cloud radiative effects on responses of rainfall to large-scale forcing during a landfall of severe tropical storm Bilis (2006). Atmos. Res., 98, 512-525, doi: 10.1016/j.atmosres.20 10.08.020. [Link]

Wang, D., X. Li, and W. K. Tao, 2010c: Torrential rainfall responses to radiative and microphysical processes of 
ice clouds during a landfall of severe tropical storm Bilis (2006). Meteorol. Atmos. Phys., 109, 107-114, doi: 10.1007/s00703-010-0097-5. [Link]

Xu, K. M. 1995: Partitioning mass, heat, and moisture bud- gets of explicitly simulated cumulus ensembles into convective and stratiform components. J. Atmos. Sci., 52,551-573, doi: 10.1175/1520-0469(1995)052<0551: PMHAMB $>2.0 . \mathrm{CO} ; 2$. [Link] 